\title{
Urgences
}

\section{Une invitée à la mort}

\section{Mario Joubert}

Numéro 10, 2e trimestre 1984

Spécial fantasmes

URI : https://id.erudit.org/iderudit/025160ar

DOI : https://doi.org/10.7202/025160ar

Aller au sommaire du numéro

Éditeur(s)

Urgences

ISSN

0226-9554 (imprimé)

1927-3924 (numérique)

Découvrir la revue

Citer ce document

Joubert, M. (1984). Une invitée à la mort. Urgences, (10), 93-101.

https://doi.org/10.7202/025160ar

Ce document est protégé par la loi sur le droit d'auteur. L'utilisation des services d'Érudit (y compris la reproduction) est assujettie à sa politique d'utilisation que vous pouvez consulter en ligne.

https://apropos.erudit.org/fr/usagers/politique-dutilisation/
Cet article est diffusé et préservé par Érudit.

Érudit est un consortium interuniversitaire sans but lucratif composé de l’Université de Montréal, l'Université Laval et l'Université du Québec à Montréal. Il a pour mission la promotion et la valorisation de la recherche. https://www.erudit.org/fr/ 
MARIO JOUBERT 


\section{UNE INVITÉE À LA MORT}

J'écarquille les yeux de la conscience sur la mort. Elle a mis ses ailes au tombeau errant de la vie. Ce spectre de tous les temps qui parfois enivre le corps, qui parfois enivre l'esprit, vient se poser en mes sens, en mes idées afin de faire de moi un de ses anges.

J'embrasse son cortège funèbre aux bras d'un délire apprivoisé par le temps. Elle sera ma lucidité, ma soif et ma vie. Je pose en son corps d'ombres mes attributs aux berges de la folie qui m'emporte en son berceau pour aller rejoindre l'infini. Je hume ce fantôme malséant aux portes de l'ivresse macabre de mes nuits... de mes jours pleins de délices pour cette noire amie de l'au-delà.

Et lorsque je l'aurai assez apprivoisée, je m'en ferai une bière afin de me reposer de toutes les ignorances de ce bas monde.

Je sens déjà ses caresses me caliner le cerveau. Elle est douce cette fille des ténèbres en mon coeur et en mon âme. Elle est attirante cette prostituée du néant dans son habit de dentelle. $\mathrm{O}$ mort j'ai du vin pour toi au délire de l'enfance folle. J'ai mon souffle à te donner, que le présent s'acharne à garder en vie, mais je sais que c'est toi qui me délivrera de ce monde amer et vide.

Par cette mort, je veux épouser sa connaissance. Je veux I'amener en ma couche afin de lui conter mes pleurs; mes rires et ma vie amère qu'il y a trop longtemps que je supporte. Par sa présence, elle me contera ses victoires et les libérations qu'elle a créées sur bien des gens. Je lui donnerai un voile de lumière et je lui demanderai de $\mathrm{m}$ 'amener avec elle.

En ma couche, je lui montrerai le dessin de ma vie afin qu'elle comprenne que, déjà, je ne suis plus de ce monde. Elle sera une amie avec laquelle je danserai, dans mes songes, sa victoire et son salut. Elle sera une amie avec laquelle j'enlève- 
rai mon corps aux vivants, ces animaux d'inconscience. Oui, en ma couche je l'inviterai à se poser à côté de moi et, alors, je l'enlacerai de mes bras moites pour rendre mon dernier sommeil à la terre, cette femme d'univers. Je lui offrirai un festin de roi, elle sera le luxe de la soirée. Elle sera mon voyage pour l'éternité.

Je lui montrerai la folie des hommes et une fois fini je lui donnerai le baiser de l'amitié. Elle sera ma toute dernière expérience. Sublime expérience, j'en suis certain, qui me transportera jusqu'aux confins de l'infini et de l'indéfini. Elle sera dès lors mon maître et mon guide.

Je poserai ma main sur son sein et le caresserai de mes mornes espoirs en invoquant l'éternel. J'assouvirai ma couche en ses bras et pleurerai la vie. Et enfin, je lui offrirai mon coeur et mon âme.

Qu'elle sera douce cette mort au creux de mon lit! Qu'elle sera bonne cette femme en me touchant de son poison mortel!

Par mes yeux épuisés de voir l'ignorance des gens, je la regarderai en pleine conscience et irai visiter son coeur et son âme. Ce sera la révélation des plus grands secrets en ce bas monde. Alors, je deviendrai roi, je deviendrai néant.

En mon, en mon âme elle a pris plus de certitudes que la vie. Elle est devenue un désir si profond et si ardent que je me désespère à ne pas avoir. Je la ferai reine et je serai son sujet.

J'irai mettre des ailes en mon âme, cette maîtresse du néant. Je lui offrirai mes connaissances afin qu'elle les étende en son lit de beaume. Je lui offrirai mes souvenirs pour qu'elle les expose sur sa couche. Oui, elle sera reine. Elle sera mon ange plein de miséricorde.

$\mathrm{O}$ mort amène-moi dans ton pays, montre-moi l'infini des choses et dis-moi où sera ma récompense ou mon affliction. J'ai déjà des larmes pour toi; j'ai déjà des rires pour toi. J'en ferai un deuil plein de parfums sauvages aux encens d'orient 
et aux arômes d'ylang-ylang.

Mon âme hume ton spectre jusqu'à se tordre. Vois-tu, elle aussi veut te visiter. Elle sera pour toi un réconfort louangeur au trépas de cette juste cause. Elle te fera voir le pays de mon corps et de mon esprit. De cette âme, je te l'offrirai au banquet de mon deuil.

Je veux mordre les ombres de ton esprit au pouvoir céleste. Je veux manger l'infini pour pouvoir te garder auprès de moi. Je veux regarder ma propre mort s'en aller avec mon corps.

O infinité des âmes suspendues aux instincts des ombres...

Je veux m'enivrer de ta douceur jusqu'à fondre en toi mes émotions. Je veux poser ma tête sur ton sein et me laisser apprivoiser par tes desseins venant de l'infini.

De cette mort, j'en ferai un gage d'amour à la terre. Et lorsque cette dernière me caressera en son ventre humide, à ce moment-là, mais juste à ce moment-là, je serai heureux... Et sur cette couche, au paroxysme de mon désir, je mordillerai tes lèvres pour savoir de quel sang tu es faite.

Je sens mes os qui t'appellent.

J'écarquille les yeux de la conscience sur la mort. Je la ferai douce et bonne en mon coeur, en mon âme comme prochain retour dans la matière subtile. J'ouvrirai mon tombeau pour m'offrir à l'infini.

Je consommerai l'éternel en mon âme.

J'éveillerai les instants des ombres au délire de ne plus être avec vous, j'invoquerai les forces de la nuit sur mon corps, dans mon âme et en mon esprit.

Déjà je meurs de ne plus être avec vous... Déjà je suis... 
J'écarterai mon tombeau des morts vivants afin de ne plus leur donner la chance de le profaner.

O âme, voici la mort qui s'en vient pour me transporter à son berceau. Voici le temps de la fin de mon temps qui vient prendre mon dernier souffle de vie. Je t'offre, ô mort, mon vin! À l'ivresse de ton pouvoir!

Ici la vie est devenue une mort certaine. Elle a meurtri mon âme jusqu'au savoir de son ombre. Elle a sucé mon sang jusqu'à la dernière goutte pour s'offrir un festin d'éternité.

Le fil de ma vie n'était pas assez solide. Maintenant il est cassé.

Déjà je ne vis plus, déjà je ne suis plus. Je meurs au tréfonds de l'éternité...

Toute mon âme est parvenue à respirer le néant.

Tout mon esprit flotte en ce fluide comme un vagabond errant. 


\section{SOLITUDE}

Le ciel en pleurs tombait à grosses gouttes. Elles embrassaient la fenêtre en faisant de petits tintements pleins de tendresse. Les rues étaient vides. La pluie devenait la seule présence.

La solitude était devenue ma compagne. Tendre compagne des jours sans fin, tendre ivresse qui se baigne dans un lac d'extase en parole et... en conscience. J'expose ton ardeur pour tous les amputés du coeur, j'exalte ta sagesse en mon âme.

Le vide avait pris toute la place. L'univers était devenu une grande solitude.

En aparté avec l'univers j'ai le secret de mon âme... avec simplicité. Dans toute simplicité on y retrouve le multiple. C'est l'ici et maintenant, le présent en tout temps. La solitude devenait tout mon être. Je suis la solitude.

- Les trésors de l'humanité sont enfouis dans le coeur de I'homme. Et le plus grand trésor c'est d'être avec soi-même en tout temps. Ça, c'est la vie. -

En cette solitude, mes pensées galopent à pleines jambes vers l'absolu. Je veille en mon corps tous les mystères de l'humanité. Ils ont le désordre dans leurs pleurs et l'ordre dans leurs rires. Ils sommeillent en chacun de nous, jusqu'au tréfonds de nous-mêmes. Ils voguent sur notre errance comme des vagabonds acharnés afin de scruter nos âmes déchirées. Sur ce, la parole doit se taire; le silence sommeille en nos paroles...

La parole est souvent la croix de la souffrance. Elle est le tombeau de la vie quotidienne. Cette grande prostituée de l'individualité enivre le coeur d'un spectre nauséabond. Nous avons tué le silence à force de le cacher derrière nos mots anodins. En ce sens, nous avons tué la vie. 
Je n'ai plus de mains, je n'ai plus d'yeux devant le fantôme parolier de la vie; de la mort. Je n'ai plus de pieds, je n'ai plus de chevilles pour marcher, pour me traîner sur des horizons d'inconscience. Les mots nous empêchent de vivre.

Je n'ai plus de voix, il me reste le silence. $\mathrm{O}$ doux silence que le rêve ne peut construire par ses images, ses mots, ses gestes et son message. La parole d'inconscience est une canaille. Elle vibre l'illusion à pleine dent. Elle se mord au regard de I'humanité.

Dehors l'averse s'est changée en crachin. Une tendresse intense accompagne ce phénomène naturel. Les rues sont toujours vides.

En mes pensées, en mes actes je mets la solitude au bout de l'errance. Je cultive un jardin en cette femme virginale. Elle est un regard pour l'humanité, pour tous les gens de coeur. Je veille en son corps, en son esprit le secret de ce que sera demain le monde. En mon corps, en mon coeur et en mon âme je couche cette solitude au creux de mon être là où les mots n'ont plus besoin d'exister. Je concocte la future sente de la tendresse. C'est la voie du juste milieu. Sur ce chemin les mots sont des vagabonds qui se prostituent par l'illusion de la connaissance. Ce sont les acrobates de la tromperie. Ils ont le regard d'une douce sirène qui cherche le désir jusqu'aux plus lointains abysses.

La solitude envahit le domaine de l'errance au multiple de la création. Nous sommes tous des enfants de la terre et nous envahissons nos âmes afin de pourvoir notre coeur de sentiments trop souvent esseulés, trop souvent illusoires. Nous sommes le destin de nos vies et nous mourons de ne pas pouvoir l'assumer. Et la vie devient une espèce de mort; et la mort devient une espèce de vie. Nous avons été trop souvent l'errance d'un chemin que l'on croyait perdu: la vie.

Le chemin... passe. II n'y a plus de chemin; il ne reste qu'un être... humain... Son rire est le chemin; ses pleurs sont 
les chemins. Il est intérieur, ils sont intérieurs. Le chemin est la vie.

Nous sommes tous des marcheurs solitaires faisant nos pas vis-à-vis l'ombre de la lumière, car il faut le dire la lumière vient de l'ombre. Elle est l'éternité venue au présent; la vie venue de la mort. Oui, nous sommes tous des solitudes marchantes qui veulent faire le "plein de monde" à l'intérieur de la vie... Nous nous cherchons comme une dualité commune. Bref, nous mourons la vie comme nous vivons notre mort. Nous sommes trop souvent "deux" alors que I' un" attend encore son unicité avec I'homme.

Nous sommes le "deux" qui n'est pas encore I'“un". Le "un" ne se divisera jamais en deux...

Nous avons tous l'unité du grand cosmos en nous... Mais nous avons accepté la division avec transport...

Et nous enfantons en ce domaine solitaire le temps comme une période de conscience. Nous nous sommes divisés au monde, nous nous sommes en ce monde construits de thébaïdes. Le chemin est intérieur, le chemin c'est le coeur. Hélas! Nous ne vivrons jamais assez pour le découvrir en entier. Nous sommes la mort de la vie et la vie de la nouvelle mort. La déroute a enfanté déjà la perdition aux multiples de l'errance. Nous sommes comme des enfants qui n'ont pas encore grandi au revers d'un monde trop souvent adulé par la sublimation imparfaite du non-espoir.

Nous avons marché aux pas d'une morose caresse de bon vin... Nous sommes tous des messagers solitaires et nous voguons sur des eaux pêle-mêle d'ivresse lointaine. Nous avons pris l'espoir par la queue... En fait, la vie nous embaume de son parfum comme pour nous dire l'arôme d'une fleur en pétales imaginatifs d'intimité.

La solitude est devenue mon secret...

En elle je sens tous les univers qui me caressent... Par elle, 
la vie, cette parturiente des instants quotidiens, enlace la virilité des jours. Je sens son ombre me caliner de douces passions. Elle est ma maîtresse, ma soeur angélique. Elle a, déjà, sa place auprès de l'éternité.

La parole est un fantôme que les nuits enlacent de leurs firmaments. Elle s'arme de fioritures afin de cacher son jeu.

En cette solitude j'ai l'âge de la terre. Toutes les prémices de l'univers sont en mon corps, en mon âme et en mon esprit. J'ai la foi de l'univers. Bref, c'est la réincarnation de l'éternité se vivant maintenant. Je suis un DIEU temporel.

La vie... est un grand silence.

Dehors le crachin s'est arrêté. Des enfants jouent en faisant des comptines. Un arc-en-ciel donne une tendresse au ciel, à la vie.

Dans le silence de mes mots je suis cette enfance. Mes paroles sont devenues des comptines, et mon âme est comme un arc-en-ciel là où je peux m'étendre afin de contempler le monde.

Je suis I'univers... qui veut donner son soleil en toute tendresse pour tous les gens.

Je suis le temps qui embrase la nature humaine, la maturité en toute féminité, en toute masculinité.

Je suis le mouvement... du temps et de I'univers qui est amour, qui est DIEU. 